\title{
Predictors of moderate ischemic mitral regurgitation improvement after off-pump coronary artery bypass
}

\author{
Xiaotian Sun, MD, ${ }^{\mathrm{a}}$ Jiechun Huang, MD, ${ }^{\mathrm{a}}$ Meng Shi, MD, ${ }^{\mathrm{a}}$ Guoqian Huang, PhD, ${ }^{\mathrm{b}}$ Liewen Pang, MD, ${ }^{\mathrm{a}}$ and \\ Yiqing Wang, $\mathrm{PhD}^{\mathrm{a}}$
}

\begin{abstract}
Objective: The aim of this study was to explore the predictors of improvement of moderate ischemic mitral regurgitation after off-pump coronary artery bypass grafting.

Methods: A prospective study was performed among 109 patients (aged $66.6 \pm$ 8.6 years, $34.6 \%$ were female) with prior myocardial infarction and moderate ischemic mitral regurgitation undergoing off-pump coronary artery bypass grafting. Preoperative and follow-up clinical characteristics and echocardiography data were analyzed, focusing on left ventricular global/regional remodeling and function. Patients were grouped by postoperative ischemic mitral regurgitation at 1 year postoperatively: the improved group with no or mild ischemic mitral regurgitation and the failure group with moderate or severe ischemic mitral regurgitation. Data were compared between the 2 groups to explore the predictors of ischemic mitral regurgitation improvement after off-pump coronary artery bypass grafting.
\end{abstract}

Results: Five patients died within 1 year and were excluded. At the 1-year followup, there were 55 patients in the improved group and 49 patients in the failure group. Before surgery, the improved group had smaller left ventricular endsystolic volume, greater left ventricular ejection fraction, greater posteriorinferior volume ratio, and earlier operation timing after infarction than the failure group. Posterior-inferior volume ratio $(P<.001)$, ejection fraction $(P=.003)$, and duration between infarction and operation $(P<.001)$ were independent predictors of preoperative moderate ischemic mitral regurgitation improvement.

Conclusions: In selected patients, preoperative moderate ischemic mitral regurgitation was relieved by off-pump coronary artery bypass grafting. Greater ejection fraction, greater posterior-inferior volume ratio, and early operation timing after infarction may predict the improvement of moderate ischemic mitral regurgitation after off-pump coronary artery bypass grafting, suggesting that posterior-inferior regional remodeling, reserved ventricular function, and early revascularization are important to the outcome. (J Thorac Cardiovasc Surg 2015;149:1606-12)

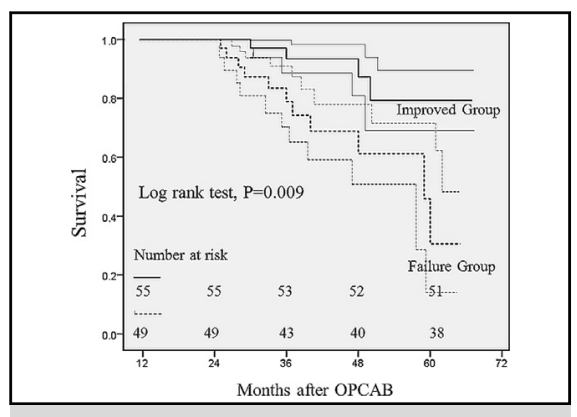

Postoperative survival estimates for patients with moderate IMR undergoing OPCAB. OPCAB, Offpump coronary artery bypass.

\section{Central Message}

In patients with moderate IMR undergoing OP$\mathrm{CAB}$, greater $\mathrm{EF}$, greater posterior-inferior volume ratio, and early operation timing after infarction may predict postoperative improvement of IMR, suggesting that posterior-inferior regional remodeling, reserved ventricular function, and early revascularization are important to the outcome.

\section{Perspective}

To date, identified predictors of IMR improvement after revascularization are scattered, especially in the LV regional remodeling aspect. The present study indicates that for patients with significant posterior-inferior regional remodeling and relatively reserved LV function, early $\mathrm{OPCAB}$ would be a benefit for IMR improvement and the outcome. These findings provide a novel perspective in predicting the improvement of IMR. Further studies with a larger sample volume and longer follow-up could establish a rational algorithm, which would combine all these factors with cutoff points and allow optimizing surgical strategies.

See Editorial Commentary page 1613.
From the Departments of Cardiothoracic Surgery a and Echocardiography, ${ }^{\mathrm{b}}$ Huashan Hospital of Fudan University, Shanghai, P. R. China.

Funded by the Health Bureau Foundation of Shanghai (Grant No. 2008076).

Received for publication Nov 5, 2014; revisions received Jan 30, 2015; accepted for publication Feb 15, 2015; available ahead of print April 9, 2015.

Address for reprints: Yiqing Wang, PhD, Department of Cardiothoracic Surgery, Huashan Hospital of Fudan University, 12th, Wulumuqi Rd, Shanghai 200040, P. R. China (E-mail: WANGYIQING1965@qq.com).

$0022-5223 / \$ 36.00$

Copyright $(\odot) 2015$ by The American Association for Thoracic Surgery

http://dx.doi.org/10.1016/j.jtcvs.2015.02.047
Ischemic mitral regurgitation (IMR) occurs frequently after myocardial infarction (MI) due to left ventricular (LV) global or regional remodeling. ${ }^{1}$ So far, the optimal strategy for moderate IMR is still controversial. Some studies had reported that combined mitral valve annuloplasty (MVA) and coronary artery bypass grafting $(\mathrm{CABG})$ could reduce IMR immediately after surgery and at follow-up ${ }^{2,3}$; however, others have shown that recurrent IMR did occur after CABG plus MVA, and no benefit for long-term 


$$
\begin{aligned}
& \text { Abbreviations and Acronyms } \\
& \begin{aligned}
\text { CABG } & =\text { coronary artery bypass grafting } \\
\text { CI } & =\text { confidence interval } \\
\text { EF } & =\text { ejection fraction } \\
\text { IMR } & =\text { ischemic mitral regurgitation } \\
\text { LV } & =\text { left ventricular } \\
\text { LVEDV } & =\text { left ventricular end-diastolic volume } \\
\text { LVEF } & =\text { left ventricular ejection fraction } \\
\text { LVESV } & =\text { left ventricular end-systolic volume } \\
\text { MI } & =\text { myocardial infarction } \\
\text { MR } & =\text { mitral regurgitation } \\
\text { MVA } & =\text { mitral valve annuloplasty } \\
\text { NYHA } & =\text { New York Heart Association } \\
\text { OPCAB } & =\text { off-pump coronary artery bypass } \\
\text { OR } & =\text { odds ratio }
\end{aligned}
\end{aligned}
$$

survival was observed. ${ }^{4,5}$ A recent randomized trial showed no greater LV reverse remodeling or clinical advantage of adding MVA to CABG at 1 year. ${ }^{6}$ There was also a tendency toward higher complication rates and mortality in CABG plus MVA compared with CABG alone in high-risk patients. ${ }^{2,6}$ Therefore, it is of concern whether moderate IMR can be reduced after CABG alone.

To date, identified predictors of IMR improvement after CABG are scattered. Penicka and colleagues ${ }^{7}$ recommended the presence of viable myocardium and the absence of dyssynchrony between papillary muscles as predictors for IMR improvement. Braun and colleagues ${ }^{8}$ demonstrated that preoperative $\mathrm{LV}$ dimension was related to reverse remodeling with IMR changes after CABG plus MVA. Jeong and colleagues ${ }^{9}$ and Fattouch and colleagues ${ }^{10}$ suggested that in patients with moderate IMR with a left ventricular ejection fraction (LVEF) $40 \%$ or less, CABG alone is not recommended because of a high incidence of recurrent mitral regurgitation (MR) and cardiac-related mortality. However, as an important mechanism of IMR, LV regional remodeling is barely studied, and the relationship between regional remodeling and IMR changes after revascularization has not been identified. The aim of this study was to identify the predictors of IMR improvement after offpump coronary artery bypass (OPCAB) by focusing on regional remodeling.

\section{MATERIALS AND METHODS \\ Study Population}

Between May 2008 and May 2013, 939 patients with left main or proximal 3-vessel disease underwent isolated CABG at Huashan Hospital of Fudan University, including 918 OPCAB cases. All patients with moderate IMR undergoing OPCAB were assessed for study eligibility by checking the following criteria: (1) prior MI by electrocardiogram or regional wall motion abnormalities by echocardiography; (2) structurally normal mitral valve; (3) available echocardiography image quality allowing 3dimensional quantitative analysis; and (4) sinus rhythm. Patients with clinical and echocardiography evidence of other cardiac structural disease, organic abnormality of the mitral apparatus, atrial fibrillation, and unstable clinical conditions were excluded. A total of 109 patients who were enrolled in the study underwent OPCAB as the only surgical procedure and accepted the same anti-ischemic and heart failure therapies. The study was approved and monitored by the institutional review board of Huashan Hospital. Each patient provided written informed consent before participation in the study. All authors had full access to and take full responsibility for the integrity of the data.

\section{Study Protocol}

At Huashan Hospital of Fudan University, patients with moderate IMR or less underwent OPCAB unless it was combined with aorta or aortic valvular lesions, whereas those with severe IMR underwent CABG and MVA. For patients with moderate IMR, preoperative clinical characteristics and echocardiography data were collected. Patients were followed up clinically and by echocardiography regularly and were grouped according to postoperative changes of IMR at 1 year after surgery: the improved group with no or mild IMR and the failure group with moderate or severe IMR. Preoperative and postoperative data were compared between the 2 groups, and predictors of IMR improvement were explored. Clinical data and 2-dimensional and 3-dimensional echocardiography were separately studied in a blind manner by 3 researchers to avoid selection bias.

\section{Preoperative Echocardiography}

Two-dimensional echocardiography. Preoperative echocardiography was performed 1 week before surgery. All patients underwent standard transthoracic echocardiogram with the Philips IE 33 system (S5-1 probe, 2.5-5.5 MHz; Philips Healthcare, Andover, Mass). MR severity was evaluated by measuring the ratio of MR color flow jet area to the left atrium area using color mapping of the apical 4-chamber view during cardiac systole, graded as mild $(<20 \%)$, moderate $(20 \%-40 \%)$, or severe $(>40 \%) .{ }^{11}$ Moderate MR was further verified by the width of the vena contracta $(0.3-0.7 \mathrm{~cm})$. The tenting area, mitral annular area, ${ }^{12}$ displacement of papillary muscles, and sphericity index were measured.

Real time 3-dimensional echocardiography. By using the $X$ 3-1 probe, datasets of each subject were stored and analyzed by QLAB 3DAdvanced Quantification software (Philips Healthcare). The software traced the endocardium border during the whole cardiac cycle and calculated the LV volume and regional volumes of 17 segments, gaining global and regional volume and function, such as the left ventricular end-diastolic volume (LVEDV), left ventricular end-systolic volume (LVESV), LVEF, volume, and EF of the posterior-inferior 5 segments (basal, mid, apical inferior segments and basal, mid inferolateral segments). The ratio of regional segments volume to LVEDV was calculated. All echocardiography parameters were standardized by body surface area.

\section{Surgical Procedures}

All surgical procedures were performed through a midline sternotomy. The left internal thoracic arteries were harvested and grafted to the left anterior descending coronary arteries in patients aged less than 75 years. Saphenous vein grafts and radial arteries (in patients aged $<60$ years) were harvested, and sequential aorto-coronary bypass grafting was performed in the remaining coronary arteries. Starfish and Octopus (Medtronic Inc, Minneapolis, Minn) devices were used in all cases. Proximal silastic snare sutures and carbon dioxide blowers were used to obtain a bloodless field. Intraluminal shunts were used during grafting. The left internal thoracic artery to left anterior descending anastomoses were performed with 7-0 Prolene sutures, and other anastomoses were performed with 6-0 Prolene sutures. Complete revascularization was performed in all cases regardless of the number or quality of lesion vessels. 


\section{Follow-up}

All clinical follow-up work was performed in a blind manner by 1 researcher from an echocardiography assessment via phone interview and outpatient visits. Patients were clinically followed up at 3 months and 6 months after surgery, and thereafter at 6-month intervals. Postoperative clinical status was prospectively determined by in-hospital and late death, latest New York Heart Association (NYHA) class during followup, cardiac hospitalization, and complications as follows: newly detected atrial fibrillation, stroke, respiratory failure, and chronic renal failure. The Kaplan-Meier survival curve was drawn to describe the survival condition. Early postoperatively, echocardiography was performed before discharge, and the echocardiography results of every patient at 1 year postoperatively (within 2 weeks before or after exactly 1 year) were gathered and analyzed.

\section{Statistical Analysis}

All statistical analyses were performed using SPSS Statistics Base 17.0 for Windows (SPSS Inc, Chicago, Ill). Continuous data were expressed as mean \pm standard deviation, and group comparisons were analyzed by unpaired and paired Student $t$ test as appropriate. The categoric variables were compared using the chi-square test. To determine the predictors of IMR improvement, binary logistic regression analysis was used. Receiver operating characteristic curve analysis was created from the obtained predictor to determine its discrimination with the highest sum of sensitivity and specificity. The actuarial survival curves were estimated by the Kaplan-Meier method, and differences between curves were analyzed by log-rank statistics.

\section{RESULTS}

There were no in-hospital deaths. Five patents died before the 1-year postoperative echocardiography assessment ( 1 died in 1 month, and 4 died after 1 month but before the 1-year postoperative assessment). The remaining 104 patients were followed up for a median of 33.0 months $\left(\right.$ Percent $_{25}=21.0$ month and Percent ${ }_{75}=46.0$ month). At 1 year postoperatively, 55 patients showed no or mild IMR and 49 patients showed moderate or severe IMR. The baseline and surgical characteristics showed no significant difference between the 2 groups except for duration between infarction and operation (Table 1).

\section{Echocardiography}

Baseline and follow-up echocardiography parameters are shown in Table 2. The 1-year postoperative echocardiography detected 45 mild cases of MR and 10 cases of no obvious MR in the improved group, and 36 moderate MR cases and 13 severe MR cases in the failure group. At baseline, patients in the improved group had significantly smaller LVESV and greater posterior-inferior volume ratio than patients in the failure group. After OPCAB, patients in the improved group showed a reduction of LVEDV, LVESV, and posterior-inferior volume and its ratio, which was not observed in the failure group. For LV global and regional function, LVEF was greater in the improved group at baseline and further improved at follow-up. Although posteriorinferior EF was similar at baseline, it increased only in the
TABLE 1. Baseline and surgical characteristics in improved and failure groups

\begin{tabular}{|c|c|c|c|}
\hline Characteristics & $\begin{array}{c}\text { Improved } \\
\text { group }(\mathbf{n}=\mathbf{5 5})\end{array}$ & $\begin{array}{c}\text { Failure } \\
\text { group }(n=49)\end{array}$ & $\begin{array}{c}P \\
\text { value }\end{array}$ \\
\hline Age, $y$ & $67.7 \pm 8.1$ & $65.4 \pm 9.0$ & .167 \\
\hline Female, n $(\%)$ & $17(30.9)$ & $18(36.7)$ & .541 \\
\hline \multicolumn{4}{|l|}{ NYHA class, $\mathrm{n}(\%)$} \\
\hline Class 2 & $8(14.5)$ & $6(12.2)$ & \\
\hline Class 3 & $45(81.8)$ & $41(83.7)$ & .939 \\
\hline Class 4 & $2(3.6)$ & $2(4.1)$ & \\
\hline Smoking, n (\%) & $11(20.0)$ & $12(24.5)$ & .640 \\
\hline Diabetes, n (\%) & $20(36.4)$ & $16(32.7)$ & .837 \\
\hline Chronic renal failure, $\mathrm{n}(\%)$ & $5(9.1)$ & $4(8.2)$ & 1.000 \\
\hline Hypertension, $\mathrm{n}(\%)$ & $22(40.0)$ & $24(49.0)$ & .430 \\
\hline COPD, n (\%) & $5(9.1)$ & $5(10.2)$ & 1.000 \\
\hline CHF, n (\%) & $4(7.3)$ & $6(12.2)$ & .511 \\
\hline IABP application, n (\%) & $5(9.1)$ & $3(6.1)$ & .719 \\
\hline \multicolumn{4}{|l|}{ Prior MI, n (\%) } \\
\hline Inferior or posterior & $23(41.8)$ & $14(28.6)$ & .218 \\
\hline Anterior & $20(36.4)$ & $24(49.0)$ & .235 \\
\hline Both & $12(21.8)$ & $11(22.4)$ & 1.000 \\
\hline \multicolumn{4}{|l|}{ Grafted coronary vessels (n, \%) } \\
\hline LAD & $51(92.7)$ & $44(89.8)$ & .732 \\
\hline LCX & $30(54.5)$ & $26(53.1)$ & 1.000 \\
\hline RCA & $33(60)$ & $23(46.9)$ & .227 \\
\hline $\begin{array}{l}\text { Duration between } \\
\text { infarction and operation, mo }\end{array}$ & $3.1 \pm 2.2$ & $4.8 \pm 1.6$ & $<.001$ \\
\hline LITA used, n (\%) & $51(92.7)$ & $44(89.8)$ & .732 \\
\hline \multicolumn{4}{|l|}{ Grafted vessels, $\mathrm{n}(\%)$} \\
\hline 3 vessels & $13(23.6)$ & $13(26.5)$ & \\
\hline 4 vessels & $36(65.5)$ & $27(55.1)$ & .462 \\
\hline 5 vessels & $6(10.9)$ & $9(18.4)$ & \\
\hline Completeness index $(\%)$ & $55(100)$ & $49(100)$ & \\
\hline Operation time, $\min$ & $220.0 \pm 34.0$ & $231.9 \pm 35.8$ & .082 \\
\hline ICU stay, h & $41.2 \pm 6.1$ & $40.8 \pm 4.5$ & .687 \\
\hline In-hospital stay, d & $10.7 \pm 1.8$ & $10.6 \pm 2.0$ & .829 \\
\hline
\end{tabular}

NYHA, New York Heart Association; COPD, chronic obstructive pulmonary disease; $C H F$, congestive heart failure; $I A B P$, intra-aortic balloon pump; $M I$, myocardial infarction; $L A D$, left anterior descending artery; $L C X$; left circumflex artery; $R C A$, right coronary artery; LITA, left internal thoracic artery; ICU, intensive care unit.

improved group postoperatively, and not in the failure group. Although leaflet tenting areas, left atrial surface areas, and papillary muscle distance were similar at baseline, they were all smaller in the improved group than in the failure group postoperatively.

\section{Predictors of Ischemic Mitral Regurgitation Improvement}

Preoperative factors with differences between groups were involved in the binary logistic regression analysis. Posterior-inferior volume ratio (odds ratio [OR], 1.815; $P<.001 ; 95 \%$ confidence interval $[\mathrm{CI}], 1.391-2.369)$, EF (OR, 1.212; $P=.003 ; 95 \%$ CI, 1.066-1.378), and duration between infarction and operation (OR, 0.521; $P<.001$; $95 \%$ CI, 0.368-0.740) were independent predictors of 
TABLE 2. Two- and three-dimensional echocardiographic data in the improved and failure groups at baseline and 1 year postoperatively

\begin{tabular}{|c|c|c|c|}
\hline & $\begin{array}{c}\text { Improved } \\
\text { group }(n=55)\end{array}$ & $\begin{array}{c}\text { Failure } \\
\text { group }(n=49)\end{array}$ & $P$ value \\
\hline \multicolumn{4}{|c|}{$\operatorname{LVEDV~}\left(\mathrm{mL} / \mathrm{m}^{2}\right)$} \\
\hline Baseline & $71.4 \pm 15.8$ & $75.3 \pm 15.7$ & 205 \\
\hline Follow-up & $65.0 \pm 8.5^{*}$ & $72.9 \pm 11.8$ & $<.001$ \\
\hline \multicolumn{4}{|c|}{$\operatorname{LVESV}\left(\mathrm{mL} / \mathrm{m}^{2}\right)$} \\
\hline Baseline & $40.5 \pm 8.8$ & $47.2 \pm 12.1$ & .002 \\
\hline Follow-up & $33.0 \pm 4.7^{*}$ & $44.5 \pm 8.5$ & $<.001$ \\
\hline \multicolumn{4}{|l|}{$\operatorname{LVEF}(\%)$} \\
\hline Baseline & $43.2 \pm 4.9$ & $37.6 \pm 7.4$ & $<.001$ \\
\hline Follow-up & $49.1 \pm 4.2^{*}$ & $38.9 \pm 6.0$ & $<.001$ \\
\hline \multicolumn{4}{|c|}{ Posterior-inferior volume $\left(\mathrm{mL} / \mathrm{m}^{2}\right)$} \\
\hline Baseline & $23.9 \pm 6.0$ & $22.4 \pm 5.2$ & .156 \\
\hline Follow-up & $19.4 \pm 3.7^{*}$ & $21.6 \pm 5.2$ & .016 \\
\hline \multicolumn{4}{|c|}{ Posterior-inferior volume/LVEDV (\%) } \\
\hline Baseline & $33.5 \pm 3.0$ & $30.0 \pm 2.5$ & $<.001$ \\
\hline Follow-up & $29.9 \pm 4.6^{*}$ & $29.6 \pm 5.0$ & .738 \\
\hline \multicolumn{4}{|c|}{ Anterior-septal volume $\left(\mathrm{mL} / \mathrm{m}^{2}\right)$} \\
\hline Baseline & $22.1 \pm 5.1$ & $23.2 \pm 5.2$ & .286 \\
\hline Follow-up & $21.6 \pm 4.8$ & $24.0 \pm 5.5$ & .018 \\
\hline \multicolumn{4}{|c|}{ Anterior-septal volume/LVEDV (\%) } \\
\hline Baseline & $33.0 \pm 13.0$ & $34.3 \pm 11.3$ & .588 \\
\hline Follow-up & $34.0 \pm 9.3$ & $34.0 \pm 9.8$ & .974 \\
\hline \multicolumn{4}{|c|}{ Posterior-inferior EF (\%) } \\
\hline Baseline & $37.2 \pm 4.9$ & $37.9 \pm 4.6$ & .460 \\
\hline Follow-up & $48.2 \pm 4.4^{*}$ & $39.2 \pm 7.1$ & $<.001$ \\
\hline \multicolumn{4}{|c|}{ Anterior-septal EF (\%) } \\
\hline Baseline & $40.2 \pm 8.4$ & $37.5 \pm 6.8$ & .073 \\
\hline Follow-up & $47.8 \pm 5.4^{*}$ & $39.7 \pm 4.7 *$ & $<.001$ \\
\hline \multicolumn{4}{|c|}{ Left atrial surface area $\left(\mathrm{cm}^{2}\right)$} \\
\hline Baseline & $20.3 \pm 4.1$ & $20.6 \pm 4.7$ & .815 \\
\hline Follow-up & $18.7 \pm 4.4$ & $23.8 \pm 5.6^{*}$ & $<.001$ \\
\hline \multicolumn{4}{|c|}{ Sphericity index } \\
\hline Baseline & $1.27 \pm 0.07$ & $1.30 \pm 0.08$ & .095 \\
\hline Follow-up & $1.27 \pm 0.10$ & $1.30 \pm 0.09$ & .183 \\
\hline \multicolumn{4}{|c|}{ Leaflet tenting area $\left(\mathrm{cm}^{2}\right)$} \\
\hline Baseline & $2.5 \pm 0.6$ & $2.6 \pm 0.7$ & .311 \\
\hline Follow-up & $1.7 \pm 0.6^{*}$ & $3.0 \pm 1.4$ & $<.001$ \\
\hline \multicolumn{4}{|c|}{ Mitral annular area $\left(\mathrm{mm}^{2}\right)$} \\
\hline Baseline & $830.6 \pm 192.6$ & $767.6 \pm 226.1$ & .128 \\
\hline Follow-up & $755.0 \pm 178.4$ & $904.3 \pm 190.3^{*}$ & $<.001$ \\
\hline \multicolumn{4}{|c|}{ Papillary muscle distance $(\mathrm{cm})$} \\
\hline Baseline & $20.6 \pm 3.4$ & $19.1 \pm 4.4$ & .055 \\
\hline Follow-up & $16.6 \pm 4.5^{*}$ & $18.4 \pm 4.1$ & .042 \\
\hline \multicolumn{4}{|c|}{ IMR jet area/LA area $(\%)$} \\
\hline Baseline & $29.5 \pm 6.3$ & $31.0 \pm 5.0$ & .205 \\
\hline Follow-up & $14.7 \pm 3.1^{*}$ & $37.4 \pm 4.6^{*}$ & $<.001$ \\
\hline
\end{tabular}

$\overline{L V E D V}$, Left ventricular end-diastolic volume; $L V E S V$, left ventricular end-systolic volume; $L V E F$, left ventricular ejection fraction; $E F$, ejection fraction; $I M R$, ischemic mitral regurgitation; $L A$, left atrial. $* P<.05$ (preoperative vs follow-up).

moderate IMR improvement after OPCAB (Table 3). Receiver operating characteristic curves defined a posterior-inferior volume ratio of $31.6 \%$, EF of $37.1 \%$, and duration between infarction and operation of 3.25 months as the cutoff values (Figure 1).
TABLE 3. Predictors of ischemic mitral regurgitation improvement by binary logistic regression analysis

\begin{tabular}{|c|c|c|c|c|}
\hline Determinants & $\begin{array}{c}\text { Coefficient } \\
\text { and } S E\end{array}$ & OR & $95 \%$ CI & $P$ value \\
\hline $\mathrm{EF}$ & $0.192 \pm 0.065$ & 1.212 & $1.066-1.378$ & .003 \\
\hline $\begin{array}{l}\text { Posterior-inferior } \\
\text { volume ratio }\end{array}$ & $0.596 \pm 0.136$ & 1.815 & $1.391-2.369$ & $<.001$ \\
\hline $\begin{array}{l}\text { Duration between } \\
\text { infarction and operation }\end{array}$ & $-0.651 \pm 0.178$ & 0.521 & $0.368-0.740$ & $<.001$ \\
\hline
\end{tabular}

\section{Clinical Outcomes}

Clinical outcomes are shown in Table 4. Four patients in the improved group and 11 patients in the failure group died during follow-up. As shown in Figure 2, patients in the improved group had greater actuarial survival than patients in the failure group at 3 years, 4 years, and 5 years postoperatively. The patients in the improved group had less newly detected atrial fibrillation and better NYHA class compared with those in the failure group.

\section{DISCUSSION}

The present study demonstrated 3 independent predictors of IMR improvement after OPCAB, including preoperative posterior-inferior volume ratio, preoperative LVEF, and duration between infarction and operation. Our results suggest that early revascularization by well-timed OPCAB would relive the moderate preoperative IMR in selected patients, especially those with significant posterior-inferior regional remodeling and reserved LV function. Furthermore, IMR improvement was accordant with the reversion of LV remodeling, improvement of the LV global and regional function, and better clinical outcomes during follow-up, which contrast finely with the patients with residual IMR. Our study might be helpful to identify the proper patients with moderate IMR who would benefit from $\mathrm{OPCAB}$, which should be important to clinical decision-making, optimization of the operation strategy, and the prognosis.

\section{Left Ventricular Regional Remodeling}

Two forms of LV remodeling are involved in the pathogenesis of IMR: global remodeling and regional remodeling. The former is frequently secondary to anterior or multisegment infarction, and dilatation of the global LV and mitral annulus are common. ${ }^{13}$ Although the latter appears more often in inferior or posterior infarction, chordae tendineae tethering due to papillary muscle displacement is the main mechanism of IMR. ${ }^{1}$ Because these 2 forms of remodeling may coexist in the same patient, identifying which is the dominant one and which is more likely to be reversed after OPCAB remains a clinical challenge. 

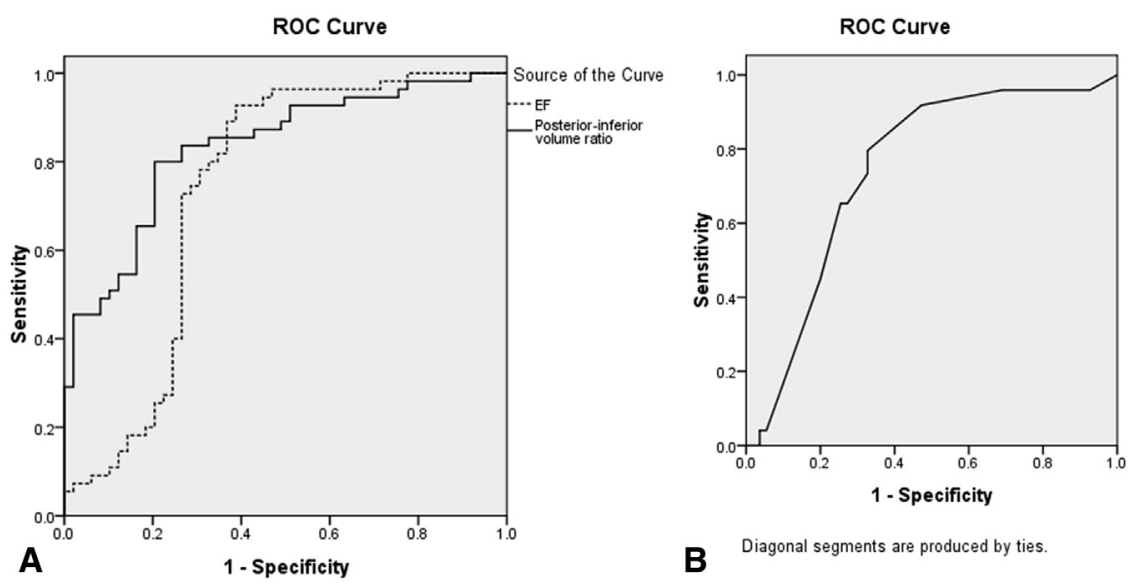

FIGURE 1. Receiver operating characteristic curves for predictors. A, Posterior-inferior volume ratio: area under the curve $=0.833(95 \% \mathrm{CI}, 0.756-$ 0.910). Cutoff value is $31.6 \%$ with a sensitivity of $80.0 \%$ and specificity of $79.6 \%$; EF: area under the curve $=0.737$ (95\% CI, $0.631-0.843)$. Cutoff value is $37.1 \%$ with sensitivity of $92.7 \%$ and specificity of $61.2 \%$. B, Duration between infarction and operation: area under the curve is $0.744(95 \%$ CI, $0.645-$ 0.842). Cutoff value $=3.25$ months with a sensitivity of $79.6 \%$ and specificity of $67.3 \%$. ROC, Receiver operating characteristic; $E F$, ejection fraction.

Patients in the improved group showed the characteristic of dominant posterior-inferior regional remodeling rather than global remodeling compared with the failure group. Soleimani and colleagues ${ }^{14}$ demonstrated that after posterolateral MI, LV global volumes and sphericity gradually increase, suggesting that regional remodeling may be considered as an early stage of LV global remodeling in certain cases. After OPCAB, the posterior-inferior segment volumes and mitral tenting areas both decreased at follow-up in the improved group, suggesting that revascularization of the posterior-inferior segments might resolve IMR by gradually improving regional wall motion, reversing regional dilatation, and lessening posterior papillary muscle tethering. Our study is consistent with many previous studies. Poh and colleagues ${ }^{15}$ reported that revascularization therapy after posterior-inferior STsegment elevation MI was associated with a lower

TABLE 4. Clinical outcomes in improved and failure groups

\begin{tabular}{lccr}
\hline & $\begin{array}{c}\text { Improved } \\
\text { group } \\
(\mathbf{n}=\mathbf{5 5})\end{array}$ & $\begin{array}{c}\text { Failure } \\
\text { group } \\
(\mathbf{n}=\mathbf{4 9 )}\end{array}$ & $\begin{array}{c}\boldsymbol{P} \\
\text { value }\end{array}$ \\
\hline Clinical follow-up, mo & $36.7 \pm 15.5$ & $32.9 \pm 14.9$ & .208 \\
Early mortality, n (\%) & $0(0)$ & $0(0)$ & \\
NYHA class, n (\%) & & & \\
Class 2 & $51(92.7)$ & $13(26.5)$ & \\
Class 3 & $3(5.5)$ & $32(65.3)$ & $<.001$ \\
Class 4 & $1(1.8)$ & $4(8.2)$ & \\
Complications, n (\%) & & & \\
Newly detected atrial fibrillation & $3(5.5)$ & $11(22.4)$ & .019 \\
Stroke & $2(3.6)$ & $4(8.2)$ & .417 \\
$\quad$ Respiratory failure & $5(9.1)$ & $6(12.2)$ & .752 \\
$\quad$ Chronic renal failure & $3(5.5)$ & $6(12.2)$ & .301 \\
Cardiac hospitalization, n (\%) & $5(9.1)$ & $7(14.3)$ & .542 \\
\hline
\end{tabular}

NYHA, New York Heart Association. incidence of IMR. Hwang and colleagues ${ }^{16}$ proved that right coronary territory revascularization resolved IMR early postoperatively.

\section{Left Ventricular Global Function}

Patients in the improved group had significantly smaller LVESV and higher LVEF, indicating reserved LV functions; preoperative LVEF greater than $37.1 \%$ was another predictor of IMR improvement. Jeong and colleagues ${ }^{9}$ showed

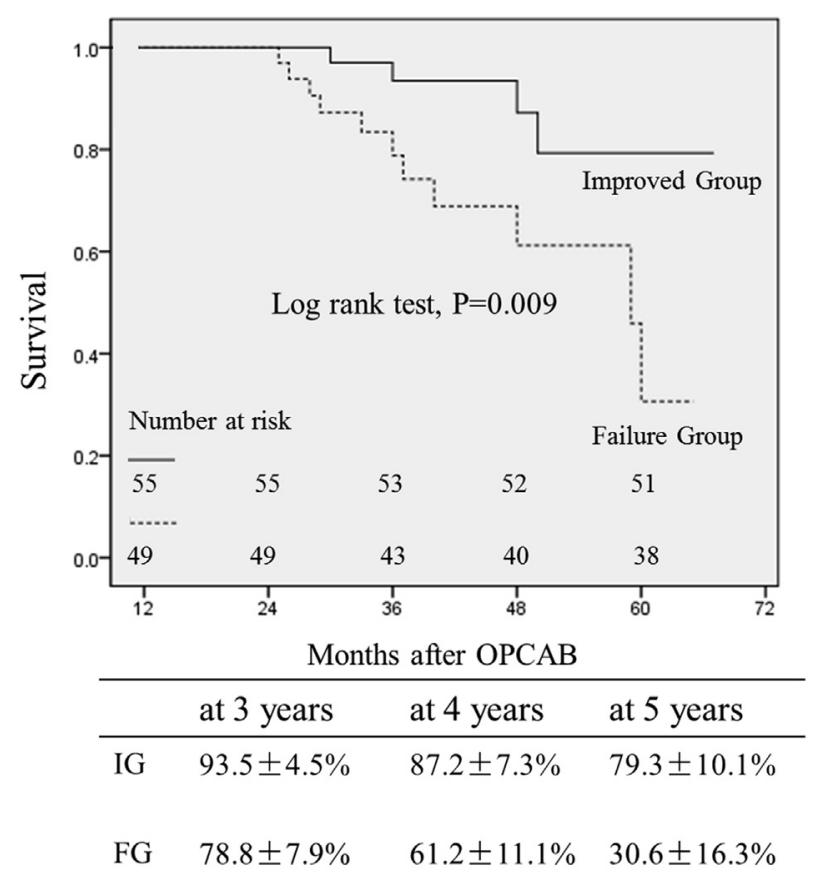

FIGURE 2. Postoperative survival estimates for patients with moderate IMR undergoing OPCAB by Kaplan-Meier. $O P C A B$, Off-pump coronary artery bypass; $I G$, improved group; $F G$, failure group. 
that for the patients with IMR and LVEF greater than $40 \%$, OPCAB was similar to CABG plus MVA regarding the freedom from recurrent IMR after 8 years. In another study conducted by Fattouch and colleagues, ${ }^{10}$ patients with moderate IMR and LVEF $40 \%$ or less usually underwent postoperative deterioration of IMR, with a high incidence of cardiac-related deaths and events.

\section{Early Opportunity for Revascularization}

In the present study, duration between infarction and operation was also an independent predictor of IMR improvement, highlighting the importance of early revascularization to the evolution of IMR and prognosis. Myocardial viability of the segments adjacent to papillary muscles warrants postoperative relief of IMR. ${ }^{7}$ The earlier revascularization is performed, the more myocardial viability is preserved. On the contrary, an animal experiment showed that for sheep models of MI and IMR over 3 months, mitral repair could not stop LV remodeling and IMR progression, ${ }^{17}$ which might explain why many studies failed to demonstrate a long-term survival benefit of CABG plus MVA compared with CABG alone. ${ }^{18}$

\section{Change in Ischemic Mitral Regurgitation and Clinical Outcomes}

Patients in the improved group had better long-term actuarial survival, improved NYHA classes, and less complications than patients in the failure group. This is in accordance with the previous study, which stated that residual and recurrent IMR after surgery negatively affected the late mortality, ${ }^{9}$ whereas moderate IMR improved after OPCAB and showed favorite survival and functional outcomes. ${ }^{19}$ This suggests that OPCAB might reverse IMR and enhance clinical outcomes for selected patients. Identifying these patients preoperatively is extremely important.

\section{Study Limitations}

First, the severity of IMR was evaluated by a semiquantitative assessment of MR color flow jet area ratio, but not by a more accurate assessment of the effective regurgitant orifice area. However, semiquantitative assessment performed by an experienced echocardiographer is still the most common method to identify significant IMR, and a combination of methods could increase the accuracy. Second, as a potential factor influencing IMR improvement after revascularization, ${ }^{7}$ myocardial viability assessment will help to enact treatment strategies. Although the post-MI period is closely associated with preserved myocardial viability, a direct assessment of myocardial viability should be performed in the future. Third, although complete revascularizations were performed in all subjects, the exact information of grafts to ischemic regions was not evaluated. Finally, the evaluation of mitral valve deformation and dysfunction in this study is relatively simple and insufficient, which could be explored in the future by realtime 3-dimensional echocardiography.

\section{CONCLUSIONS}

OPCAB could improve IMR and outcomes for selected patients with moderate IMR. Posterior-inferior regional remodeling (posterior-inferior volume ratio $>31.6 \%$ ), reserved $\mathrm{LV}$ function ( $\mathrm{EF}>37.1 \%$ ), and early revascularization (within 3 months after MI) can predict the improvement of moderate IMR. Thus, for patients with significant posterior-inferior regional remodeling and relatively reserved LV function, early OPCAB would help; however, for the patients with dominant LV global dilatation, severe dysfunction, and a long history of MI, concomitant MVA might be suggested for unpredictable IMR changes. Further studies with a larger sample size and longer follow-up term are warranted to establish a rational algorithm in the future, which would combine all the factors with cutoff points and allow optimizing surgical strategies. To accomplish this, each patient should be evaluated comprehensively and treated individually.

\section{Conflict of Interest Statement}

Authors have nothing to disclose with regard to commercial support.

\section{References}

1. Kumanohoso T, Otsuji Y, Yoshifuku S, Matsukida K, Koriyama C, Kisanuki A, et al. Mechanism of higher incidence of ischemic mitral regurgitation in patients with inferior myocardial infarction: quantitative analysis of left ventricular and mitral valve geometry in 103 patients with prior myocardial infarction. J Thorac Cardiovasc Surg. 2003;125:135-43.

2. Chan KM, Punjabi PP, Flather M, Wage R, Symmonds K, Roussin I, et al. Coronary artery bypass surgery with or without mitral valve annuloplasty in moderate functional ischemic mitral regurgitation: final results of the Randomized Ischemic Mitral Evaluation (RIME) trial. Circulation. 2012;126:2502-10.

3. Timek TA, Hooker RL, Collingwood R, Davis AT, Alguire CT, Willekes CL, et al. Five-year real world outcomes of GeoForm ring implantation in patients with ischemic mitral regurgitation. J Thorac Cardiovasc Surg. 2014;148:1951-6.

4. Bouchard D, Jensen H, Carrier M, Demers P, Pellerin M, Perrault LP, et al. Effec of systematic downsizing rigid ring annuloplasty in patients with moderate ischemic mitral regurgitation. J Thorac Cardiovasc Surg. 2014;147:1471-7.

5. Rabbah JP, Siefert AW, Bolling SF, Yoganathan AP. Mitral valve annuloplasty and anterior leaflet augmentation for functional ischemic mitral regurgitation: quantitative comparison of coaptation and subvalvular tethering. J Thorac Car diovasc Surg. 2014;148:1688-93.

6. Smith PK, Puskas JD, Ascheim DD, Voisine P, Gelijns AC, Moskowitz AJ, et al Surgical treatment of moderate ischemic mitral regurgitation. $N$ Engl J Med. 2014;371:2178-88

7. Penicka M, Linkova H, Lang O, Fojt R, Kocka V, Vanderheyden M, et al. Predictors of improvement of unrepaired moderate ischemic mitral regurgitation in patients undergoing elective isolated coronary artery bypass graft surgery. Circulation. 2009;120:1474-81.

8. Braun J, Bax JJ, Versteegh MI, Voigt PG, Holman ER, Klautz RJ, et al. Preoperative left ventricular dimensions predict reverse remodeling following restrictive mitral annuloplasty in ischemic mitral regurgitation. Eur J Cardiothorac Surg. $2005 ; 27: 847-53$

9. Jeong DS, Lee HY, Kim WS, Sung K, Park PW, Lee YT. Off pump coronary artery bypass versus mitral annuloplasty in moderate ischemic mitral regurgitation. Ann Thorac Cardiovasc Surg. 2012;18:322-30.

10. Fattouch K, Sampognaro R, Speziale G, Salardino M, Novo G, Caruso M, et al Impact of moderate ischemic mitral regurgitation after isolated coronary artery bypass grafting. Ann Thorac Surg. 2010;90:1187-94. 
11. Bonow RO, Carabello BA, Chatterjee K, de Leon AC Jr, Faxon DP, Freed MD, et al. 2008 Focused update incorporated into the ACC/AHA 2006 guidelines for the management of patients with valvular heart disease: a report of the American College of Cardiology/American Heart Association Task Force on Practice Guidelines (Writing Committee to Revise the 1998 Guidelines for the Management of Patients With Valvular Heart Disease): endorsed by the Society of Cardiovascular Anesthesiologists, Society for Cardiovascular Angiography and Interventions, and Society of Thoracic Surgeons. Circulation. 2008;118: 523-661.

12. Rossi A, Dini FL, Faggiano P, Agricola E, Cicoira M, Frattini S, et al. Independent prognostic value of functional in patients with heart failure. A quantitative analysis of 1256 patients with ischaemic and non-ischaemic dilated cardiomyopathy. Heart. 2011;97:1675-80.

13. Otsuji Y, Kuwahara E, Yuge K, Yotsumoto G, Ueno T, Nakashiki K, et al. Relation of aneurysmectomy in patients with advanced left ventricular remodeling to postoperative left ventricular filling pressure, redilatation with ischemic mitral regurgitation. Am J Cardiol. 2005;95:517-21.

14. Soleimani M, Khazalpour M, Cheng G, Zhang Z, Acevedo-Bolton G, Saloner DA, et al. Moderate mitral regurgitation accelerates left ventricular remodeling after posterolateral myocardial infarction. Ann Thorac Surg. 2011;92:1614-20.
15. Poh KK, Lee GK, Lee LC, Chong E, Chia BL, Yeo TC. Reperfusion therapies reduce ischemic mitral regurgitation following inferoposterior ST-segment elevation myocardial infarction. Coron Artery Dis. 2012;23:555-9.

16. Hwang HY, Lim JH, Oh SJ, Paeng JC, Kim KB. Improved functional mitral regurgitation after off-pump revascularization in acute coronary syndrome. Ann Thorac Surg. 2012;94:1157-65.

17. Beaudoin J, Levine RA, Guerrero JL, Yosefy C, Sullivan S, Abedat S, et al. Late repair of ischemic mitral regurgitation does not prevent left ventricular remodeling: importance of timing for beneficial repair. Circulation. 2013;128:S248-52.

18. Gelsomino S, Lorusso R, Caciolli S, Capecchi I, Rostagno C, Chioccioli M, et al. Insights on left ventricular and valvular mechanisms of recurrent ischemic mitral regurgitation after restrictive annuloplasty and coronary artery bypass grafting. $J$ Thorac Cardiovasc Surg. 2008;136:507-18.

19. Fukui T, Takanashi S, Tabata M, Hosoda Y. Mild or moderate ischemic mitral regurgitation in patients undergoing off-pump coronary artery bypass grafting. J Card Surg. 2007;22:480-5.

Key Words: coronary artery bypass grafting, mitral regurgitation, myocardial infarction, myocardial remodeling

Readers who found these articles interesting may also like to read the following papers found in recent and future issues of our sister publications, Seminars in Thoracic and Cardiovascular Surgery and Operative Techniques in Thoracic and Cardiovascular Surgery!

\section{Acquired Cardiovascular Disease: Valvular Heart Disease}

Current Readings: Tirone David. Aortic Valve Sparing Operations. Semin Thorac Cardiovasc Surg. Autumn 2014;26(3):231-238.

News and Views: Rakesh Suri. Mitral Valve Repair in Asymptomatic Patients with Severe Mitral Regurgitation: Pushing Past the Tipping Point. Semin Thorac Cardiovasc Surg. Summer 2014;26(2):95-101.

News and Views: Michael Reardon. The CoreValve US Pivotal Trial. Semin Thorac Cardiovasc Surg. Autumn 2014;26(3):179-86.

Ravi Ghanta. Staged Hybrid Repair for Extent II Thoracoabdominal Aortic Aneurysms and Dissections. Oper Tech Thorac Cardiovasc Surg. Summer 2014;19(2):238-251.

Gorav Ailawadi. Transcatheter MV repair. Oper Tech Thorac Cardiovasc Surg. Summer 2014;19(2):219-237. 